\title{
A HISTÓRIA EM PERMANENTE ESTADO DE CRISE? CONSIDERAÇÕES SOBRE CRÍTICA, MODERNIDADE E CONHECIMENTO HISTÓRICO A PARTIR DE MICHEL FOUCAULT
}

\author{
The history in permanent state of crisis? Considerations on criticism, modernity and historical \\ knowledge from Michel Foucault
}

Jacson Schwengber*

\begin{abstract}
Resumo: O presente artigo inicia com diagnósticos, contemporâneos e modernos, de uma crise do conhecimento histórico. Atualmente, fala-se em um possível esgotamento do conceito moderno de história. No entanto, a partir da leitura de Michel Foucault argumenta-se que: muito do que se entende como ataque aos valores da modernidade e/ou do Iluminismo já se encontrava presente no pensamento dos próprios autores modernos. A trajetória de Pierre Bayle (1647-1706) é utilizada como exemplo para corroborar essa hipótese. A noção de crítica formulada por Michel Foucault é o ponto articulador para se tecer considerações em dois sentidos: 1) formas alternativas de se repensar a ideia de modernidade; 2) alternativas ao que tem sido entendido como um regime de historicidade presentista.
\end{abstract}

Palavras-chave: Crítica, Modernidade, Historiografia.

\begin{abstract}
The present article begins with diagnoses, contemporaneous and modern, of a crisis of historical knowledge. Nowadays, there is talk of a possible exhaustion of the modern concept of history. However, from the reading of Michel Foucault it is argued that: much of what is understood as an attack on the values of modernity and/or of the Enlightenment was already present in the thinking of the modern authors themselves. Pierre Bayle's (1647-1706) trajectory is used as an example to corroborate this hypothesis. The notion of criticism formulated by Michel Foucault is the articulating point to make considerations in two senses: 1) alternative ways of rethinking the idea of modernity; 2) alternatives to what has been understood as a presentist regime of historicity.
\end{abstract}

Keywords: Criticism, Modernity, Historiography.

(...) qual é então esse acontecimento que se chama a Aufklärung e que determinou, pelo menos em parte, o que somos, pensamos e fazemos hoje? ${ }^{1}$

No início dos anos dois mil, o historiador francês Roger Chartier reuniu em uma série de artigos alguns pontos que desde o final da década de 1980 "inquietavam" os historiadores. Com a metáfora da história à beira da falésia, tratou das frequentes constatações quanto as crises e incertezas que nos últimos anos foram anunciadas acerca da historiografia. No panorama daí traçado, o otimismo e a confiança dos anos 1970 parecia ter dado lugar a "um

\footnotetext{
${ }^{*}$ Possui graduação em História-licenciatura pela Universidade Federal do Rio Grande do Sul (2011). Mestre em história pela Universidade Federal do Rio Grande do Sul (2016). Doutorando em História pelo Programa de Pós-graduação em História da Universidade Federal do Rio Grande do Sul (PPHH-UFRS). Bolsista CNPq.

${ }^{1}$ FOUCAULT, Michel. Ditos e Escritos II. Rio de Janeiro: Forense Ed., 2015, p.351.
} 
tempo de dúvidas e interrogações”. Contudo, Chartier observava que a constatação de alguns autores de que as ciências humanas, e entre elas a história, passavam por um momento de crise, não deve ser aceita sem reservas. Para ele "proclamar, depois de muitos outros, que as ciências sociais estão em crise não basta para estabelecê-lo".

Ainda assim, os enunciados de crise existem. Passado mais de uma década destes textos, o quadro parece persistir. Em seu último livro, lançado na França em 2013, François Hartog afirma que continuamos a habitar um presente "que não termina nunca de se diagnosticar como estando em crise". O tom do historiador tem notas bastante melancólicas quanto ao saber histórico: "Com o fim do século XX, a história parece ter passado de toda poderosa a impotente". Em artigo recentíssimo, Arthur Lima de Avila questiona se "não seria a "crise contínua' um dos signos recorrentes, ao menos retóricos, da historiografia contemporânea?"”.

A ideia de uma crise de inteligibilidade do conhecimento histórico teria sido reforçada, entre outros motivos, pelas formulações "radicais" da chamada virada linguística (linguistic turn): "a perigosa redução do mundo social a uma pura construção discursiva, a meros jogos de linguagem”. Para o historiador italiano Carlo Ginzburg, a ampla aceitação da dimensão retórica da história teria obliterado o compromisso desse saber com a "prova" e a veracidade. Nos últimos decênios as teses céticas, as quais reduzem o conhecimento histórico à sua dimensão narrativa ${ }^{5}$, teriam ganhado maior espaço. Segundo ele, no atual cenário intelectual "a ideia de que os historiadores possam provar algo parece a muitos antiquada e até ridícula" ${ }^{6}$.

O desafio colocado por teses céticas ${ }^{7}$ ou a percepção de uma situação de crise não constituem necessariamente uma novidade, embora digam respeito a questões específicas de cada conjuntura. Em 1689, o católico Pierre Paulian questionava se não seria possível colocar

\footnotetext{
${ }^{2}$ CHARTIER, Roger. À Beira da Falésia: a história entre incertezas e inquietude. Porto Alegre: Ed. da UFRGS, 2002, p.65.

${ }^{3}$ HARTOG, François. Crer em História. Belo Horizonte: Autêntica, 2017, p.43 e p.25.

${ }^{4}$ AVILA, Lima de. Indisciplinando a historiografia: do passado histórico ao passado prático, da crise à crítica. Revista Maracanan, Rio de Janeiro, jan./jun. 2018, p.40.

${ }^{5}$ No ano de 2012, as conferências realizadas no âmbito do 6 Seminário Brasileiro de História da Historiografia (SNHH), problematizaram a noção de giro linguístico. O vento teve como título: "O Giro Linguístico e a Historiografia: balanço e perspectivas". Nesse mesmo ano, a edição de junho da American History Review, dedicou um fórum para a questão, "Historiografical tuns in critical perspective", onde são oferecidos artigos que fazem um balanço dos impactos das teorias da linguagem no campo historiográfico anglo-americano. Na edição número 17, de abril de 2015, da revista História da Historiografia, publicou um caderno especial dedicado ao tema. Cf https://www.historiadahistoriografia.com.br/revista, última consulta 05/09/2017. Para o mapeamento dos efeitos do chamado giro linguístico na historiografia brasileira, ver em especial CEZAR, Temístocles. O Hamlet Brasileiro: ensaio sobre giro linguístico e indeterminação historiográfica (1970-1980). História da Historiografia, Ouro Preto, n.17, 2015, pp-440-461.

${ }^{6}$ GINZBURG, Carlo. Relações de Força. História, Retórica, Prova. São Paulo: Cia das Letras, 2004, p.13.

${ }^{7}$ Para a atualidade do tema, não só nas discussões historiográficas, vale destacar a edição número 394, de 2001, da Le Magazine Littéraire, na qual foi publicado um dossiê com o título "le retour des sceptiques".
} 
o seu tempo como "a época do pirronismo histórico?". No interior das contendas confessionais do século XVII, esse autor ainda se perguntava se esse pirronismo colocaria as gerações vindouras os mesmos paradoxos e embaraços no qual os homens de seu tempo se encontravam ${ }^{8}$. Em 1702, Jacob Perizonius abordou a mesma questão em sua aula inaugural na Universidade de Leiden. O tema era o pirronismo histórico e o reputado professor anunciava que a história estava em plena crise ${ }^{9}$.

Correta ou não, a preocupação de Perizonio parece não ter sido sem razão. De acordo com o historiador Franklin L. Baumer o pirronismo histórico estava disseminado nos ambientes letrados do final do século XVII. Os problemas teológicos e filosóficos (que estão necessariamente imbricados no período) tinham um pano de fundo traumático para os europeus - se é lícito usar esse termo. As guerras religiosas na França, a guerra civil inglesa, a Revogação do Édito de Nantes e o fanatismo religioso fizeram eco nas obras de Montaigne, Hobbes e Pierre Bayle. O espírito de sectarismo teria cindido a unidade social, por isso haveria urgência em "transcender a controvérsia", a qual era alimentada pela dúvida ${ }^{10}$. A história, por sua vez, era um universo duvidoso por excelência: "no século XVII, disputas religiosas e políticas haviam invadido a história e desacreditado o historiador. Facilmente percebiam-se opiniões em tudo, e a conclusão natural foi desacreditar toda a tribo dos historiadores ${ }^{11}$ ".

Os contextos sociais, políticos e culturais de finais do século XVII e do início do século XVIII são bastante diversos daqueles do final século XX e início do XXI. Porém, parece que algumas questões modernas fazem eco nas formulações contemporâneas. Se no período moderno toda a comunidade dos historiadores foi posta em suspeição, não foi perguntado contemporaneamente se "ainda cremos em história? ${ }^{12 "}$

A dúvida enunciada por Hartog tem relação com modalidades discursivas de se experienciar o tempo. O conceito moderno de história teria perdido legitimidade. Isso não porque se duvide de seu rigor metodológico e de sua factibilidade empírica, mas porque se questiona sua pertinência: "a História e a historiografia (processo e disciplina) perderam sua eficácia frente a um futuro catastrófico e ameaçador ${ }^{13}$ ".

\footnotetext{
${ }^{8}$ PULIAN, Pierre. Critique des lettres pastorales de M. Jurieu. Lyon: Anisson, Posuel \& Rigaud, MDCLXXXIX [1689].

${ }^{9}$ HAZARD, Paul. Crise da Consciência Europeia. Lisboa: Cosmos, 1971 (1934), p.37.

${ }^{10}$ BAUMER, Franklin L. O Pensamento Europeu Moderno: séculos XVII e XVIII. volume I. Rio de Janeiro: editora 70, 1977.

${ }^{11}$ MOMIGLIANO, Arnaldo. História Antiga e o Antiquário. Anos 90, Porto Alegre, v.21, n.39, 2014, p. 30.

${ }^{12}$ HARTOG, François. Crer em História, p.9.

${ }^{13}$ PEREIRA, Mateus H.F; ARAUJO, Valdei Lopes de. Reconfigurações do tempo histórico: presentismo, atualismo e solidão na modernidade digital. Revista UFMG, Belo Horizonte, 2016, v.23, N. 1 e 2, p.277.
} 
Como o próprio Hartog indica nos seus estudos mais recentes, o futuro como catástrofe não é uma peculiaridade da atualidade. Desde a Primeira Guerra Mundial, passando pelo medo de inverno nuclear na Guerra Fria, a catástrofe aparece como uma realidade ou como uma possibilidade no horizonte. No entanto, de diferentes formas, a história (ou melhor, a filosofia da história) conseguia se apresentar como uma alternativa utópica possível, guardando assim pelo menos uma de suas características do conceito moderno: planejar o futuro. As crises, uma vez deflagradas, exigem uma tomada de decisão. Nesse sentido, as diferentes filosofias da história funcionavam como recurso para antecipar ou orientar essa decisão. Ou, nos casos de risco de catástrofes, a perspectiva histórica indicaria como conseguir evitá-las ${ }^{14}$. No entanto, hoje não se acreditaria mais nessa função da história e nessa descrença se configura a situação de crise $^{15}$.

Na perspectiva que vou adotar, a conformação do pensamento dito moderno e o que é entendido ainda hoje como crise andam lado a lado. Em algumas interpretações todo o quadro é visto como um estado de crise permanente — gestada na modernidade e ainda operante. Para Koselleck, o século XVIII foi "a antecâmara da época atual": a atual crise mundial resulta da história europeia", a qual "expandiu-se em história mundial e cumpriu-se nela, ao fazer com que o mundo inteiro ingressasse em um estado de crise permanente". Nas formulações do historiador alemão, o estado de crise, inicialmente um dado do velho continente, tem determinado os eventos políticos globais desde então ${ }^{16}$. Dessa forma, o século XVIII não só teria nos legado o quadro de nosso pensamento, como a sua constante situação de crise.

\section{REPENSAR A MODERNIDADE}

Não faz muito tempo, o papel das mídias de massa, em especial televisão e jornal, eram lugares comuns nos debates sobre a formação da opinião pública. A tópica não desapareceu de todo. No entanto, outro suporte e um novo veículo tomaram conta das pautas: a internet e as redes sociais. Novas palavras referentes aos ambientes digitais foram adicionadas ao léxico jornalístico e sociopolítico, por exemplo: bolha, algoritmo e pós-verdade. Essas palavras têm sido utilizadas para descrever uma crise mais ampla na circulação e checagem de informações. Dentre elas, a noção de "pós-verdade" teve seu uso ampliado de forma exponencial em 2016, data em que foi escolhida como a palavra do ano pelo Dicionário Oxford. Em uma breve

\footnotetext{
${ }^{14}$ KOSELLECK, Reinhart. Crítica e Crise - Uma contribuição à patogênese do mundo burguês. Rio de Janeiro: Contraponto/EdUERJ, 1999.

15 HARTOG, François. Regimes de Historicidade: presentismo e experiências do tempo. Belo Horizonte: Autêntica, 2014; HARTOG, François. Crer em História.

${ }^{16}$ KOSELLECK, Reinhart. Crítica e Crise - Uma contribuição à patogênese do mundo burguês. p.10.
} 
definição etimológica do termo, o Oxford esclarece que o prefixo "pós-" (post-) não designa um marco cronológico. Não se trata da delimitação de um momento após uma situação específica ou evento (como pós-guerra ou pós 11 de Setembro, por exemplo). O prefixo em pós-verdade significa algo como "pertencendo a um momento em que o conceito especificado tornou-se sem importância ou irrelevante ${ }^{17 "}$.

O termo, então, pretende expressar no que consiste a situação na qual se está inserido nesse momento. Denota uma qualidade substantiva do próprio presente. Da mesma forma que operam atualmente expressões como "pós-democracia ${ }^{18 "}$ ou “pós-humano ${ }^{19 "}$. Pós-verdade é definido como um adjetivo que "está relacionado ou que denota circunstâncias nas quais fatos objetivos têm menos influência na formação da opinião pública do que o apelo a emoção e crenças pessoais ${ }^{20}$ ". O conceito e o fenômeno que ele pretende designar estão postos na pauta do dia. Em publicação do dia 16 de novembro de 2016, na página online do jornal Washington Post, o tom foi categórico: “É oficial: a verdade está morta. Fatos são do passado 21 ".

O que teria provocado isso? Para o jornalista conservador Metthew d'Ancona a causa é evidente: uma infecção relativista que, disfarçada de ceticismo legítimo, estaria se espalhando pelos espaços do debate público. Em seu livro Post-truth: the new war on truth and how to figth Back, o nome de Donald Trump e o processo eleitoral que o levou à Casa Branca são mencionados diversas vezes. Porém, menos que uma reportagem, o autor quis tratar de questões relacionadas ao conhecimento, sua natureza e sua transmissão. Segundo ele, os valores modernos estão em risco e conclama a defesa do legado dos filósofos ilustrados:

Esta não é uma batalha entre liberais e conservadores. É uma batalha entre duas maneiras de perceber o mundo, duas abordagens fundamentalmente diferentes da realidade: e entre essas duas, você precisa escolher. Você está satisfeito que os valores centrais do Iluminismo, das sociedades livres e do discurso democrático sejam destruídos por charlatões — ou não? ${ }^{22}$.

\footnotetext{
${ }^{17}$ Ver: https://en.oxforddictionaries.com/word-of-the-year/word-of-the-year-2016 última consulta 08/02/2018.

${ }^{18}$ Quanto a isso ver: BALLESTRIN, Luciana Maria de Aragão. Rumo a uma teoria pós-democrática? Pelotas (RS): $41^{\circ}$ encontro da Anpocs, outubro de 2017.

${ }^{19}$ Quanto a isso ver: SANTAELLA, Lucia. Pós-humano - por quê? São Paulo: Revista USP, n.74, junho/agosto 2007, p.126-137.

${ }^{20}$ Para a definição e a etimologia do termo remeto a página do Oxford https://en.oxforddictionaries.com/word-ofthe-year/word-of-the-year-2016 última consulta 08/02/2018.

21 Para conferir a postagem da notícia remeto ao link: https://www.washingtonpost.com/news/thefix/wp/2016/11/16/post-truth-named-2016-word-of-the-year-by-oxford-dictionaries/?utm_term=.6acacbf3e4ae

${ }^{22}$ This is not a battle between liberals and conservatives. It is a battle between two ways of perceiving the world, two fundamentally different approaches to reality: and as between those two, you do have to choose. Are you content for the central value of the Enlightenment, of free societies and of democratic discourse, to be trashed by charlatans - or not? D'Ancona, Metthew. Post-truth: the new war on truth and how to figth Back. (Kindle E edition), 2017.
} 
Para o jornalista, as raízes desse charlatanismo está no que ele chama de pósmodernismo. Na verdade, d'Ancona parece reativar um modus operandi e uma tópica já bem conhecidos no debate teórico das humanidades nos últimos anos ${ }^{23}$.

Para a historiadora Gertrude Himmelfarb, o Iluminismo é para os pós-modernos o que o Antigo Regime fora para a Revolução Francesa. Em outros termos: a Ilustração simbolizaria a ideia moderna contra a qual o pós-modernismo se revolta. Para a historiadora:

o Iluminismo (Enlightenment), o qual foi primordialmente um movimento de ideias, é especialmente vulnerável deste tipo de ceticismo intelectual. O 'projeto Iluminista', como é algumas vezes equivocadamente dito, é pensado como obsoleto, uma ilusão ou desilusão da modernidade ${ }^{24}$.

Para o cientista político Robert C. Barlett, o pós-modernismo, e os movimentos inspirados nele, tem constantemente questionado e minado as bases de sustentação da racionalidade iluminista, as quais conformaram o quadro do pensamento ocidental moderno. A afirmação é uma acusação, pois as tendências relativistas atuais poderiam acarretar graves consequências para a organização política e social; colocando em risco "a segurança e os confortos da democracia liberal" (sic). O "colapso da razão", celebrado como uma conquista que possibilitaria uma sociedade tolerante com todas as diferenças e alteridades, acabaria, pelo contrário, abrindo espaço para o obscurantismo de toda espécie. Por isso, defende a necessidade, segundo ele urgente, de se reexaminar as origens do projeto político e filosófico moderno - uma forma de alerta para quão altas podem ser as apostas "em ridicularizar o Iluminismo e suas conquistas políticas ${ }^{25}$ ".

Discordo das proposições feitas por d'Anconna, Himmelfarb e Barllet a respeito daquilo que chamam de pós-moderno e/ou ceticismo. Aquilo que por eles é apresentado como uma desconstrução do pensamento e dos valores ocidentais modernos pode ser, na verdade, o desvelamento de outros aspectos não considerados desse mesmo pensamento. Como contraponto ao que vou chamar aqui de modelo normativo do moderno (ou padrão hegemônico da modernidade), me apoiarei em alguns autores que evidenciam "as variações e as

\footnotetext{
${ }^{23}$ De acordo com a historiadora Joan Scott, não raro, colegas de ofício, intelectuais públicos das mais diversas áreas, politicos e jornalistas consideram o pós-modernismo "responsible for all manner of ethical lapses, ranging from the decline of academic standards (plagiarism, lack of attention to factual accuracy, radical scepticism about truth and the possibility of objectivity) to the vagaries of multiculturalism (disunity, loss of coherence and shared focus), the erosion of society's moral center, the defeat of working-class political movements, tolerance for violations of universal human rights in the name of cultural relativism, and even to the 11 September terrorist attacks in New York City and Washington, D.C". SCOTT, Joan W. History-writing as critique In: JENKINS, Keith; MORGAN, Sue; MUNSLOW, Alun (orgs). Manifestos for History. London: Routledge, 2007. p.19.

${ }^{24}$ HIMMELFARB, Gertrude. The Roads to Modernity: the British, French, and American Enlightenments. Vintage Books, 2005, p.10.

${ }^{25}$ BARLETT, Robert C. Introduction In: BAYLE, Pierre. Various Thoughts on The Occasion of Comet. Abany: State of New York Press, 2000, p.xxiv.
} 
descontinuidades na experiência moderna" e "a natureza descentrada e indiscutivelmente plural das subjetividades modernas ${ }^{26 \%}$.

A forma como frequentemente são colocadas as ideias de pós-moderno e ceticismo enfatiza suas potencialidades de ruptura catastrófica ${ }^{27}$ com o passado estável e seguro da modernidade. Talvez por isso, "pouca atenção é dada a possibilidade de que grande parte do que é identificado como pós-moderno possa ter sido pressagiado ou prefigurado nos contornos da própria modernidade ${ }^{28,}$.

Himmelfarb afirma existir "atualmente uma considerável literatura sobre o 'projeto Iluminista', como ele é chamado (geralmente pejorativamente), começando por uma das fontes dessa crítica, Michel Foucault". Para a historiadora, o texto "O que são as Luzes" é uma das principais referências mobilizadas contra os valores ilustrados ${ }^{29}$. Não há dúvidas que nesse texto são colocados em questão muitos dos parâmetros de legitimação do pensamento ocidental. Porém, ele não consiste propriamente em um ataque ${ }^{30}$. Na verdade, como argumentarei, tratase de uma tentativa de repensar a modernidade de forma criativa e crítica.

O século XVIII europeu, de acordo com interpretações hoje canônicas, glorificou a razão de diversas formas e viu nela a suprema faculdade humana ${ }^{31}$. O dogmatismo da fé na razão é colocado como o elemento que caracteriza o Iluminismo ${ }^{32}$. Essas interpretações que evidenciam, não sem razão, aspectos de um racionalismo quase dogmático reforçam a

\footnotetext{
${ }^{26}$ GILROY, Paul. O Atlântico Negro: modernidade e dupla consciência. São Paulo: editora 34, 2001, p.110.

${ }^{27} \mathrm{Em}$ um texto que também procura pensar sobre a natureza do que se tem diagnosticado como crise da historiografia, Arthur Lima de Avila fez uma crítica enfática a essa percepção catastrofista do pós-moderno: "o mote da 'irracionalidade', quando não da 'barbárie', dos supostos 'pós-modernos' foi recorrente ao longo dos debates teóricos das décadas de 1980 e 1990, quando historiadores e historiadoras com os mais diferentes posicionamentos teóricos e políticos se insurgiram contra os 'bárbaros no portão', numa reação absolutamente desmesurada àquilo que era, acima de tudo, um debate teórico sobre os limites do conhecimento histórico. Com isso, na demonstração brilhante de LaCapra, eles e elas visavam menos debater a sério as proposições dos ditos 'pós-modernos', um significante vazio, do que interditar politicamente de antemão certas questões - foi o caso, aqui no Brasil, das exortações de Ciro Cardoso contra o 'pós-modernismo’ em suas mais diferentes formas, por exemplo. O resultado foi a criação de espantalhos que pouco ou nada tinham a ver com os problemas teóricos em questão e que transformaram o 'pós-modernismo', e tudo associado com ele ('virada linguística', 'desconstrução', 'narrativismo', etc.), em uma figura 'fantasmagórica' e 'demoníaca' destinada a destruir a historiografia e, por consequência, a civilização ocidental (como se a segurança de uma decorresse evidentemente da saúde da outra...)" AVILA, Arthur Lima de. O fim da História e o fardo da temporalidade. No prelo, 2018 (?).

${ }^{28}$ GILROY, Paul. O Atlântico Negro: modernidade e dupla consciência, p.103.

${ }^{29}$ HIMMELFARB, Gertrude. The Roads to Modernity: the British, French, and American Enlightenments, p.190.

${ }^{30}$ Não se trata de ignorar as críticas que Foucault de fato dirigiu contra formas de controle justificadas por critérios supostamente racionais. Em Vigiar e Punir, sua crítica se dirigiu ao conjunto de dispositivos que dão sustentação ao sistema penal no ocidente. Nesse estudo, descreve um conjunto de práticas e de saberes que em nome do valor "justiça" não faz outra coisa que controlar e excluir. O "projeto Iluminista", em sua manifestação jurídica atual, é apresentado como um processo, no mínimo, ambíguo: "As 'Luzes' que descobriram as liberdades inventaram também as disciplinas" (FOUCUALT, 1999, p.245).

${ }^{31}$ CASSIRER, Ernst. A Filosofia do Iluminismo. Campinas: ed. Unicamp, 1994.

${ }^{32}$ GADAMER, Hans-Georg. Verdade e Método: traços fundamentais de uma hermenêutica filosófica. Petrópolis: Vozes, 1997.
} 
caracterização de um modelo normativo do pensamento moderno. Porém, é possível fazer uma leitura alternativa:

(...) se fala frequentemente da modernidade como uma época ou, em todo caso, como um conjunto de traços característicos de uma época; ela é situada em um calendário, no qual seria precedida de uma pré-modernidade, mais ou menos ingênua ou arcaica, e seguida de uma enigmática e inquietante 'pósmodernidade'.

(...) pergunto-me se não podemos encarar a modernidade mais como uma atitude do que como um período da história ${ }^{33}$.

Para poder pensar no que consiste essa atitude, é necessário fugir da "chantagem intelectual e política" que exige que se tomem posições "a favor" ou "contra" a modernidade e/ou ao Iluminismo: "não se trata um comportamento de rejeição. Deve-se escapar à alternativa do fora e do dentro". Essa atitude moderna deve ser apreendida através da "pesquisa histórica dos acontecimentos que nos levaram a nos constituir e a nos reconhecer como sujeitos do que fazemos, pensamos, dizemos ${ }^{34}$,.

\section{O QUE É A CRÍTICA?}

Em $O$ que são as Luzes, ensaio originalmente publicado em 1984, fica evidente pelo título a intenção de traçar um paralelo com o famoso texto de Kant escrito duzentos anos antes: was ist Aufklärung $?^{35}$ Em seu texto, Foucault procura resgatar aquilo que ele entende como a principal característica do Esclarecimento (ou a característica que ele quer valorizar): a resistência à autoridade. A filósofa Judith Butler avalia que dificilmente algum pensador "iluminista" concordaria coma a interpretação de Foucault, "todavia essa resistência não invalida sua caracterização, pois o que o autor busca, no Iluminismo, é resgatar aquilo que permanece 'impensado' dentro de seus próprios termos ${ }^{36}$ ".

Para poder extrair do Iluminismo um conteúdo que nos termos ilustrados permanecia “impensado", Foucault pratica história. Ou melhor, seu relato é uma história crítica ${ }^{37}$. Para entender como ele mobilizou cada um desses termos ("história" e "crítica"), pode ser útil revisitar algumas proposições suas anteriores ao ano de 1984 e que, em certa medida, abriram caminho para a redação de $O$ que São as Luzes?

No dia 27 de maio de 1978, Michel Foucault proferiu uma palestra com o título: "O que é a crítica? ". O recorte temporal e geográfico feito por Foucault segue, em linhas gerais, marcos

\footnotetext{
${ }^{33}$ FOUCAULT, Michel. Ditos e Escritos II, p.358.

${ }^{34}$ FOUCAULT, Michel. Ditos e Escritos II, p.364.

${ }^{35}$ A partir daqui farei referência ao título em português, conforme tradução consultada: "Resposta a pergunta: Que é Esclarecimento? In KANT, Immanuel. Textos seletos. Petrópolis: ed. Vozes, 1985.

${ }^{36}$ BUTLER, Judith. O que é a crítica? Um ensaio sobre a virtude de Foucault. USP:Cadernos de Ética e Filosofia Política, São Paulo, 2013, N.22, p. 167.

${ }^{37}$ BUTLER, Judith. O que é a crítica? Um ensaio sobre a virtude de Foucault, p.167.
} 
já consagrados: algum momento entre os séculos XIV e XVI na Europa. No entanto, o caminho que ele escolhe para fazer essa história é que leva a conclusões originais quanto à questão que dá título à sua conferência.

O termo "crítica" em si tem uma história de longa duração, sua configuração no interior da cultura europeia moderna, teve sua gênese nos trabalhos eruditos de Joseph Scaliger, por volta de 1575. O conjunto de palavras que se associam ao conceito, nas diversas línguas nacionais da Europa, foi apropriado do latim por volta de 1600. Desde então, ganhou importância ascendente nos meios cultos do continente. As regras de exegese, que conformam a crítica textual, foram formuladas pelos humanistas dos séculos XV e XVI. Todavia, nesse primeiro momento moderno, as operações filológicas mobilizadas eram pouco sistematizadas e, por vezes, arbitrárias. A crítica não era ainda uma arte ou um ofício formalizado. Foi no final do século XVII que aqueles que se autodenominavam críticos (critici) e que entendiam sua prática letrada como crítica (critice) tentaram, com diferentes graus de sucesso, criar uma teoria e um modelo metodológico padronizado ${ }^{38}$. Mas, para Foucault não interessava pensar a crítica como esse objeto e essa prática que se sistematiza, essa teoria que se formaliza ou esse corpo de saber que se acumula. Ele não pensou a crítica como um capítulo restrito à história da erudição. Seu tema não era um método e suas variações. O que ele fez foi identificar e descrever a gênese histórica de uma atitude.

Seu relato começa pela pastoral cristã que, no final da Idade Média, desenvolveu a ideia "que cada indivíduo, quais sejam sua idade, seu estatuto, e isso de uma extremidade a outra da sua vida e até no detalhe de suas ações, devia ser governado e devia se deixar governar". Se deixar governar significava que para a alma ser salva ela tinha que ser conduzida por alguém. Nessa configuração o sujeito se encontrava enredado num sistema meticuloso e detalhado de obediência ${ }^{39}$.

Para poder conduzir era preciso uma arte de governar. Arte no sentido de técnica, a qual comporta preceitos, regras e métodos. Na igreja romana latina, por séculos, um conjunto de saberes de direcionamento das condutas e dos pensamentos foi reunido no que se chamava ars artium, cujo significado preciso é "direção de consciência". Essas artes de governar, em um dado momento, se deslocam de seu núcleo original (religioso e conventual) para espaços cada

\footnotetext{
${ }^{38}$ BRAVO, Benedetto. Critice in the Sixteenth and Seventeenth Centuries and the Rise of the Notion of Historical Criticism In: QUANTIN, Jean-Louis; LIGOTA, Christopher. History of Scholarship. Oxford: University Press, 2006.

${ }^{39}$ FOUCAULT, Michel. O que é a crítica? (conferência proferida em 27 de maio de 1978), tradução de Gabriela Lafetá Borges e revisão de Wanderson Flor do Nascimento, disponível em http://michelfoucault.weebly.com/textos.html
} 
vez mais amplos da sociedade. Com isso se constituíram novos domínios e com eles variações de artes de governar: "como governar as crianças, como governar os pobres e os mendigos, como governar uma família, uma casa, como governar os exércitos, como governar os diferentes grupos, as cidades, os Estados, como governar seu próprio corpo ${ }^{40}$ ".

Como governar talvez tenha sido o grande tema entre os séculos XV e XVI: "questão fundamental a qual respondeu a multiplicação de todas as artes de governar — arte pedagógica, arte política, arte econômica ${ }^{41}$ ". Porém, correlato desse mesmo fenômeno, formulou-se também a questão: como não ser governado?

(...) nessa grande inquietude em torno da maneira de governar e na pesquisa sobre as maneiras de governar, localiza-se uma questão perpétua que seria: 'como não ser governado assim, por isso, em nome desses princípios, em vista de tais objetivos e por meio de tais procedimentos, não dessa forma, não para isso, não por eles ${ }^{42}$.

Deste enredo histórico é que se apresenta, nos termos de Foucault, uma primeira definição da crítica: "a arte de não ser de tal forma governado ${ }^{43}$ ”. A crítica, segundo ele, não pode ser definida por uma teoria geral, mas sempre em relação a um objeto ao qual ela se direciona: o direito, a literatura, a arte, a cultura, etc. Dessa forma, não é dela mesma que se busca uma apreensão do que seria sua natureza. É na pesquisa histórica que ele busca ancoragem para definir algo como uma "atitude crítica". Ela teria se manifestado pela primeira vez no ocidente nos acontecimentos em torno da Reforma Protestante — ou mesmo antes em diversos movimentos heréticos que desafiavam a direção da hierarquia eclesiástica.

\section{PRESENTE, ATUALIDADE E CRÍTICA PERMANENTE DO “SER HISTÓRICO"}

Fazendo um salto cronológico para o final do século XVIII, Foucault dirá que essa definição de crítica típica do início do período moderno, não se distancia daquela apresentada no Resposta a Pergunta: Que é Esclarecimento? ${ }^{44}$ Porém, a forma como o questionamento é elaborado e desenvolvido por Kant representa um deslocamento: "o esboço do que se poderia chamar de atitude de modernidade ${ }^{45}$ ". Essa outra definição não está desvinculada da que a precedeu e diz respeito a uma forma de se relacionar com o presente. A ideia de atitude de modernidade parte da forma como a crítica se relaciona com a atualidade. Não se deve esquecer

\footnotetext{
${ }^{40}$ FOUCAULT, Michel. O que é a crítica?, p.3.

${ }^{41}$ FOUCAULT, Michel. O que é a crítica?, p.3.

${ }^{42}$ FOUCAULT, Michel. $O$ que é a crítica?, p.3.

${ }^{43}$ FOUCAULT, Michel. O que é a crítica?, p.4.

${ }^{44}$ Contudo, essa definição não deve ser buscada naquilo que Kant definiu em seus tratados monumentais com o nome "crítica". Mas, pela forma como ele define, nesse breve artigo de jornal, o que é Aufklärung: "o que Kant descrevia como a Aufklärung, é o que eu tentei até agora descrever como a crítica". FOUCAULT, Michel. O que é a crítica?, p.6.

${ }^{45}$ FOUCAULT, Michel. Ditos e Escritos II, p.357.
} 
que esse texto de Kant era um artigo de jornal. Responder o que é Aufklärung era um tema da atualidade $^{46}$ : “um pouco como nós nos colocaríamos a questão: o que é a crise dos valores atuais ${ }^{47 \%}$.

O tipo de interrogação que está enraizada na Aufklärung kantiana problematiza simultaneamente: sobre nossos modos de ser histórico, sobre nossas constituições como sujeitos e a relação disso com o presente. Por isso, a relação estabelecida com a modernidade e as Luzes não é de fidelidade aos elementos de uma doutrina: "o fio que pode nos atar dessa maneira à Aufklärung é a reativação permanente de uma atitude (...) um êthos filosófico que seria possível caracterizar como crítica permanente de nosso ser histórico ${ }^{48}$ ".

A reativação permanente dessa atitude abre uma agenda para realização de uma série de pesquisas históricas com o máximo de rigor crítico possível. Um tipo de conhecimento histórico que não se volta unicamente para o passado, mas que se relaciona com a atualidade e é capaz de colocar questionamentos aos fundamentos do mundo em que se vive; de desnaturalizar hierarquias sociais e políticas do presente. Empreendimento histórico-crítico enraizado no presente, porém não presentista. Em um gesto de inversão e atualização do projeto kantiano, com Foucault a crítica se converte numa forma de abertura para o futuro:

A crítica é certamente a análise dos limites e a reflexão sobre eles. Mas, se a questão kantiana era saber a que limites o conhecimento deve renunciar a transpor, parece-me que, atualmente, a questão crítica deve ser revertida em uma questão positiva: no que nos é apresentado como universal, necessário, obrigatório, qual é a parte do que é singular, contingente e fruto das imposições arbitrárias. Trata-se, em suma, de transformar a crítica exercida sob a forma de limitação necessária em uma crítica prática sob a forma de ultrapassagem possível ${ }^{49}$.

Mesmo que seus dados sejam recolhidos em arquivos que se referem ao passado, a história crítica de Foucault tem como dimensão temporal de análise o presente. Não para racionalizá-lo como o ponto inevitável para onde tudo o que antes foi feito culminou, nem no sentido conservador de manutenção do status quo. Tampouco para ficar preso a ele. Mas avaliar como, apesar de sua relação tensa e descontínua com o passado, o presente pode ter aberturas para pensar o futuro; qual a forma de ultrapassagem possível.

Do objeto original da crítica erudita moderna, eminentemente textos, muitos outros se desdobram: condições sociais, práticas, formas de conhecimento, poder e discurso. Uma série

\footnotetext{
${ }^{46}$ De fato, na mesma edição deste famoso opúsculo de Kant encontra-se um outro tema cotidiano debatido na época: “é conveniente sancionar ulteriormente o vínculo conjugal através da religião?”. KANT, Immanuel. Textos Seletos. Petrópolis: Ed. Vozes, 1985, p.100.

${ }^{47}$ FOUCAULT, Michel. O que é a crítica?, p.28.

${ }^{48}$ FOUCAULT, Michel. Ditos e Escritos II, p.361.

${ }^{49}$ FOUCAULT, Michel. Ditos e Escritos II, p.364.
} 
de aproximações históricas tem que ser feita a cada vez e em cada caso: "esse tipo de escrita crítica da história serve os interesses historiográficos em dois sentidos: abre portas para futuros que de outra forma não poderíamos imaginar e, ao fazê-lo, nos dá mais material para a escrita da história ${ }^{50 "}$. Pensar a prática historiográfica como crítica, não poderia ser uma via possível para se escapar ao que se tem chamado de crise do tempo? Deixemos essa questão em aberto. Antes, gostaria de fazer algumas considerações, tomando a trajetória de um autor moderno como exemplo disso que Foucault chamou atitude crítica e atitude moderna.

\section{PIERRE BAYLE E A CRÍTICA MODERNA}

A crítica não funciona como censura ou juízo, tampouco é uma espécie de manual de lógica. Sua tarefa primordial "não será avaliar se os seus objetos são bons ou ruins, altamente valorizados ou menosprezados, mas sim por em relevo a própria estrutura de avaliação ${ }^{51}$ ". Foucault não é colocado como o único teórico do século XX a pensar a crítica nesses termos, ao seu lado estão nomes como os de Theodor Adorno, Raymond Williams e Jacques Derrida ${ }^{52}$. Joan Scott vai além, e recua essa perspectiva até o século XIX. Para ela, Marx e Nietzsche, em muitos de seus escritos, também representam esse tipo de crítica. $\mathrm{O}$ primeiro desconstruindo categorias naturalizadas da Economia Política, bem como os parâmetros das histórias oficiais, escritas conforme os quadros de referência de regimes burgueses ${ }^{53}$. O segundo em praticamente todos os seus trabalhos procurou desestabilizar valores consagrados da cultura ocidental: a razão, a metafísica filosófica, a moral e a própria ideia de verdade.

Minha proposta é que esse deslocamento possa ser recuado para o final do século XVII, mais precisamente na figura de Pierre Bayle (1647-1706). Não se pretende cometer o exagero anacrônico de supor que ele tenha pensado nos mesmos termos de autores contemporâneos. Ainda que muitas de suas ideias se aproximem daquilo que foi chamado acima de atitude crítica. Tampouco traçar uma narrativa teleológica na qual Bayle figure como uma espécie de precursor. No entanto, acredito que seu caso pode ser ilustrativo da pluralidade de perspectivas

\footnotetext{
${ }^{50}$ SCOTT, Joan W. History-writing as critique, p.35.

${ }^{51}$ BUTLER, Judith. O que é a crítica? Um ensaio sobre a virtude de Foucault, p.162.

${ }^{52}$ SCOTT, Joan W. History-writing as critique; BUTLER, Judith. O que é a crítica? Um ensaio sobre a virtude de Foucault.

${ }^{53}$ A historiadora destaca um trecho da Crítica da Filosofia de Hegel, texto escrito por Marx entre dezembro de 1843 e janeiro de 1844, aos seus 25 anos de idade: "A tarefa imediata da filosofia, que está a serviço da história, é, depois de desmascarada a forma sagrada da autoalienação [Selbstentfremdung] humana, desmascarar a autoalienação nas suas formas não sagradas. A crítica do céu transforma-se, assim, na crítica da terra, a crítica da religião, na crítica do direito, a crítica da teologia, na crítica da política". MARX, Karl. Crítica da Filosofia do Direito de Hegel. São Paulo: Boitempo, 2010, p.146. De acordo com a leitura que Scott faz de Marx, a forma de "desmascarar a autoalienação" não seria a partir de aprioris teóricos e filosóficos, mas a partir da análise de "situações históricas concretas". Entende que, para Marx, a escrita da história poderia ser uma das formas que a crítica poderia tomar, ou seja, uma forma de compreender aquilo que nos circunda. SCOTT, Joan W. Historywriting as critique, p.24.
} 
possíveis para se pensar a epistemologia produzida no período moderno. Também penso que seus trabalhos têm um interesse particular para a história da historiografia, uma vez que ele escreveu história como crítica. Embora, talvez, nem ele mesmo tenha pensado sua prática nesses termos.

Se comparado com nomes da geração que o precedeu (Descartes, Bacon ou Galileu, por exemplo), seu nome é menos lembrado. Também seus contemporâneos mais ilustres costumam receber maior atenção (Newton, Locke e Leibniz, entre eles). No paralelo com a geração que o sucedeu a situação é ainda mais assimétrica, estudos de luminares da ilustração como Hume e Voltaire possuem bibliografia muito mais ampla. Porém, quando seu trabalho é avaliado, muitas vezes os termos que o descrevem são hiperbólicos:

\begin{abstract}
Bayle não fez muito menos pela história do que Gali1eu pela física. Galileu exige a independência total da física em relação ao texto bíblico para a interpretação dos fenômenos, impõe e justifica metodicamente essa exigência: Bayle abre o caminho dessa independência em história. Foi ele quem realizou, mutatis mutandis a revolução copernicana em história. Em vez de basear a 'verdade' da história num pretenso dado objetivo imposto dogmaticamente pela Bíblia ou pela Igreja, ele retorna às fontes subjetivas, às condições subjetivas dessa verdade. A crítica das fontes históricas, que lhe serviu de ponto de partida, adquire em suas mãos uma amplitude cada vez maior até converter-se numa espécie de 'crítica da razão histórica' ${ }^{54}$.
\end{abstract}

Exageros à parte, sua relevância é destacada por importantes historiadores que pesquisam sobre o período moderno e o Iluminismo ${ }^{55}$. No entanto, a hipótese que gostaria de testar aqui é que através de alguns de seus escritos também é possível identificar uma atitude de modernidade. Seu nome está vinculado a um dos grandes debates de sua época. No Setecentos, o conceito de crítica estava no centro das questões literárias, filosóficas e políticas. O debate sobre quais os objetos, procedimentos e limites da crítica se converteu no "tema do século ${ }^{56}$. Pierre Bayle teve um papel fundamental nessa discussão e suas concepções, direta ou indiretamente, foram decisivas para própria definição do conceito e suas modalidades de aplicação posteriores.

Desde a juventude, Pierre Bayle se dedicou ao estudo da história. Leitor de Montaigne, teria pego gosto pelos dados "concretos". Suas correspondências registram muitos eventos contemporâneos - campanhas militares, disputas entre correntes filosóficas, assuntos

\footnotetext{
${ }^{54}$ CASSIRER, Ernst. A Filosofia do Iluminismo, p.279.

55 ROBERTSON, John. The Case for the Enlightenment: Scotland and Naples (1680-1760). New York: Combridge University Press, 2005; ISRAEL, Jonathan Irvine. Enlightenment Contested: Philosophy, Modernity, and the Emancipation of Man 1670-1752. New York: Oxford University Press, 2006; ISRAEL, Jonathan Irvine. Radical Enlightenment: philosophy and the making of modernity (1650-1750). New York: Oxford Press, 2001; GRAFTON, Anthony. As Origens Trágicas da Erudição: pequeno tratado sobre notas de rodapé. Campinas: Papirus, 1998.

${ }^{56}$ KOSELLECK, Reinhart. Crítica e Crise - Uma contribuição à patogênese do mundo burguês. p.103.
} 
religiosos e teológicos, etc. Nas suas cartas nota-se que "cedo percebeu a dimensão ideológica do poder político, que essa ideologia se apoia sobre crenças religiosas ou racionais ${ }^{57}$ ”.

Pensadores contemporâneos — como os já mencionados: Butler, Scott e Foucault entendem que a crítica não tem a pretensão de regular e ordenar. Ou seja, não formula um sistema filosófico normativo. A prática intelectual de Bayle se pautou em perspectiva semelhante. Em seus livros avaliava diferentes teorias, situava-as em seus contextos originais e as comparava entre si; tudo isso não para construir um sistema alternativo, mas para desmontar os existentes. Por isso, é classificado muitas vezes como cético — ou mesmo ultracético. Porém, Bayle entendia estar fazendo crítica.

Desde sua carreira universitária em Sedan e depois em Roterdã, fez da crítica um tipo de análise dos limites. Nesses dois lugares ministrou aulas de história e filosofia. Na sua trajetória professoral sabia fazer o trânsito de um domínio ao outro. Antes mesmo de publicar seus primeiros livros as semelhanças, diferenças e as possíveis articulações desses conhecimentos, fizeram parte de sua reflexão ${ }^{58}$.

Chamado de "campeão dos modernos", não parece que possa ser enquadrado em uma ideia de modernidade caracterizada pelo dogma racional. Suas proposições foram, no mínimo, atípicas, e aqui interessam para uma ideia mais plural da modernidade. Como crítico não concedeu prevalência a nenhum critério avaliativo, mas descreveu as próprias estruturas de avaliação. O que levava a paradoxos aparentes, como sua afirmação escandalosa para a época: "uma coisa pode ser verdade na filosofia e falsa na teologia", ou vice-versa ${ }^{59}$.

Com esse paradoxo, na verdade ele minava a própria ideia de verdade. Se uma mesma proposição pode ser tomada como verdadeira ou falsa, dependendo apenas se considerada do ponto de vista do teólogo ou do filósofo, logo não se poderia decidir sobre uma verdade em si. Por isso, seu dicionário histórico e crítico não descrevia significado de palavras e conceitos. A maioria dos verbetes são pequenos resumos biográficos (e a breve história de algumas cidades). Assim, podia tratar as ideias não como fenômenos puramente abstratos, mas ancoradas em disputas localizadas e motivadas por trajetórias individuais específicas: "quase nunca leio os historiadores com o intento de me instruir das coisas que se passaram, mas somente para saber aquilo que se diz em cada nação e em cada partido sobre as coisas que se passaram ${ }^{60}$ ".

\footnotetext{
${ }^{57}$ BOST, Humbert. Propõe Bayle uma história da filosofia? Revista Kriterion, Belo Horizonte, 2009, n 120, p.297.

${ }^{58}$ BOST, Humbert. Propõe Bayle uma história da filosofia?, p.296.

${ }^{59}$ BAYLE, Pierre. Dictionnaire Historique et Critique. Roterdã: chez Reinier Leers, tomo II, MDCXCVII [1697], p.110.

${ }^{60}$ BAYLE, Pierre. Ouves diverses. Vol. 2, Haya: Compagnie des Libraries, 1737, p.106.
} 
A disposição tipográfica do Dicionário Histórico e Crítico é parte indissociável do princípio crítico que o orienta. Não há hierarquia de importância quanto aos assuntos, pois estão dispostos em ordem alfabética. Seus temas são particulares, restritos e não há pretensão de realizar uma história narrativa que tenha meio, início e fim. Tampouco existe a intenção de totalidade. Tomemos um exemplo: no Dicionário encontramos verbetes sobre Aristóteles e Espinosa, mas nenhum sobre Platão ou Descartes. Por quê? O autor não justifica.

Porém, seu pensamento não é nenhuma espécie de negacionismo temporão. Não foi um irracionalista, se por isso se compreender a recusa a qualquer tipo de objetividade. Pelo contrário, seus trabalhos demonstram imensa erudição ${ }^{61}$ e extremo rigor na análise da autenticidade dos textos que consultou. Seu ceticismo era filosófico, não necessariamente histórico. Duvidava das pretensões das grandes verdades morais e religiosas. Não via na razão uma espécie de entidade meta-histórica ou como fundamento suficiente para sustentar um ponto de vista global de toda realidade empírica: "a história da filosofia não pode ser aquela de uma verdade que se desdobraria progressivamente: ela não é mais que os esforços feitos pelas pessoas para se compreenderem, entenderem o mundo e a história ${ }^{62}$.

Sua escala de análise era o singular e o localizado, sem pretensões à compreensão verdadeira do todo. As ideias abstratas e gerais seriam dotadas de força igual, de igual probabilidade e aniquilando-se umas às outras ${ }^{63}$ ". Em seus exercícios intelectuais "pesava incessantemente o 'pour et contre' e esbarrava em contradições que produziam novas contradições". No Dicionário Histórico e Crítico, “a razão se dissolvia, por assim dizer, em um exercício constante da crítica ${ }^{64 "}$. De acordo com Ernst Cassirer “dificilmente um só dos fatos coletados por Bayle ainda apresenta para nós, materialmente falando, um interesse particular". Mas é esse gesto crítico e sua forma de problematizar que consistem em sua originalidade e sua importância na história do pensamento moderno ${ }^{65}$.

Em Bayle, o exercício crítico não é a emissão de um julgamento, pois julgar acabaria por mascarar a arbitrariedade dos próprios critérios de juízos. A atitude judicativa se caracteriza por mobilizar categorias para qualificar um determinado objeto, ao final esse objeto é compreendido, catalogado e hierarquizado conforme essas categorias prévias: “os juízos

\footnotetext{
${ }^{61}$ Estima-se que no Dicionário Histórico e Crítico são referenciados 3756 títulos de autores modernos, e que ao longo dos artigos são citados cerca de 267 autores da antiguidade. ALMEIDA, Maria Cecília P. de. O Elogio da Polifonia: Tolerância e Política em Pierre Bayle. São Paulo: tese de doutoramento em filosofia FFLCH/USP, 2011.

${ }^{62}$ BOST, Humbert. Propõe Bayle uma história da filosofia?, p.310.

${ }^{63}$ HAZARD, Paul. Crise da Consciência Europeia, p.90.

${ }^{64}$ KOSELLECK, Reinhart. Crítica e Crise - Uma contribuição à patogênese do mundo burguês, p.96.

${ }^{65}$ CASSIRER, Ernst. A Filosofia do Iluminismo, p. 276.
} 
operam como maneiras de subsumir um particular a uma categoria já constituída. A crítica, ao contrário, visa a desvendar a constituição oclusiva do campo das próprias categorias ${ }^{66 "}$.

O Dicionário, que provavelmente foi a obra mais lida do século XVIII, dificilmente seria reeditada integramente hoje. Seus mais de dois mil artigos, contando com aproximadamente seis milhões de palavras, e versando sobre personagens absolutamente marginais na história do pensamento moderno, dificilmente teria apelo comercial. Seu valor está no apelo que fazia aos seus leitores para que avaliassem as razões para se crer e se duvidar. Sua crítica, como uma atitude, é uma prática na qual se coloca em questão os limites de nossos modos de conhecimento mais certos.

Paul Ricoeur certa vez definiu Bayle como "o duvidador de múltiplos alvos", e o colocou ao lado de Espinosa, Richard Simon, Mabillon e Papebroeck, como um dos representantes da "idade de ouro" da crítica histórica ${ }^{67}$. Para Hubert Bost, a atitude de Bayle em relação ao conhecimento assume a nuance e a hesitação: "se a disciplina filosófica envolve questionar as evidências, um dos seus motores é necessariamente a dúvida: devemos duvidar para nos colocar a pensar ${ }^{68 "}$. A dúvida não era um objetivo, mas um meio; é a condição para poder pensar e converte a crítica em um processo sempre em andamento. A história estudada como crítica é um gesto de abertura para o futuro e para um regime de verdade que ainda não se conhece: “em Bayle, o crítico só tem uma obrigação: a obrigação em relação ao futuro ${ }^{69}$ ".

\section{O PROBLEMA ÉTICO DA CRÍTICA}

No presente, são atribuídos epítetos a Bayle, tais como: "pensador assistemático", "filósofo do paradoxo", "mosaico" e "enigma"70. Talvez sejam reveladores do tipo de questionamento implicado pela crítica — seja a dele ou aquela proposta séculos depois por Foucault. A crítica não parece ser capaz de reparar as fissuras que ela mesma provoca. Aparentemente sabe só fazer interrogações. O que suscita a pergunta: “como é possível pôr em questão a pretensão exaustiva que essas regras de ordenação têm sobre a certeza, sem se enredar na incerteza, sem habitar aquele campo de indeterminação que nos suscita as acusações de imoralidade, maldade e ceticismo ${ }^{71}$ ".

\footnotetext{
${ }^{66}$ BUTLER, Judith. O que é a crítica? Um ensaio sobre a virtude de Foucault, p.160.

${ }^{67}$ RICOEUR, Paul. A memória, a história, o esquecimento. Campinas: Unicamp, 2007, p.183.

${ }^{68}$ BOST, Humbert. Propõe Bayle uma história da filosofia?, p.307.

${ }^{69}$ KOSELLECK, Reinhart. Crítica e Crise - Uma contribuição à patogênese do mundo burguês, p.97.

${ }^{70}$ ALMEIDA, Maria Cecília P. de. O Elogio da Polifonia: Tolerância e Política em Pierre Bayle.

${ }^{71}$ BUTLER, Judith. O que é a crítica? Um ensaio sobre a virtude de Foucault, p.170. Para esse tipo de acusação de imoralidade feitos contemporaneamente remeto a nota 22 acima. Para um paralelo dessa problemática no período moderno Joan DeJean afirma que "tanto no século XVII, quanto hoje, as Guerras Culturais marcam um período de intensa divisão em que a sociedade passa a crer primeiramente que a civilização como a conhecem está prestes a acabar, e, em seguida, que os fatores literários são sintomáticos deste declínio e também responsáveis
} 
Distante do perigo real da fogueira da Inquisição Católica, no seu refúgio na Holanda, Pierre Bayle não conseguiu escapar da condenação moral e pública. Mesmo entre os protestantes seus livros eram muitas vezes tidos como coleções de infâmias e indecências: “o requisitório mais terrível que foi redigido para vergonha e confusão dos homens ${ }^{72}$ ". Em uma edição da Bibliotheque germanique, um artigo anônimo registra: “é de notoriedade pública que as obras do Sr. Bayle encheram de dúvidas um grande número de leitores, e difundiram incertezas sobre princípios da Religião e da Moral que eram os mais universalmente aceitos"73.

A crítica envolve uma dimensão ética e epistemológica de abertura para o futuro. No entanto, esse futuro é indeterminado. Geralmente esse aspecto é entendido como sinal de insuficiência para promover transformações sociais e políticas. Sem um mapa claro ou um plano definido do que virá a seguir, a atitude crítica só faria desorientar. As ponderações feitas aos limites da crítica não são sem fundamento, afinal: “podemos pensar, é claro, que uma certeza epistemológica é necessária para que se afirme, com convicção, que o mundo é e deve ser ordenado de dada maneira". Ao que se poderia devolver: "até que ponto essa certeza não é arquitetada pelas formas de conhecimento, precisamente a fim de obliterar a possibilidade de um pensar diferente? ${ }^{74 \%}$.

Foucault definia suas pesquisas como "estudos de história", embora não tomasse suas atividades como trabalhos de historiador. Em suas visitas aos arquivos a pergunta que se fazia era: “em que medida o trabalho de pensar sua própria história pode liberar o pensamento daquilo que ele pensa silenciosamente, e permitir-lhe pensar diferente ${ }^{75}$ ". Porém, essa definição que entende a história como uma forma de abertura para formas alternativas de pensamento, não faz cessar as objeções à crítica. Conforme Butler, um contraponto recorrente ao trabalho de Foucault se dá da seguinte forma: “o que há de bom em um pensar diferente se não sabemos de antemão se esse pensar produzirá um mundo melhor? ${ }^{76 "}$

Outra vez a pergunta é importante e talvez, como todo grande questionamento filosófico, permanecerá em aberto. O que parece equivocado é reduzir a importância ética e política da crítica, muitas vezes tomada como niilismo acadêmico. No caso concreto de Pierre Bayle, suas ideias, direta ou indiretamente, tiveram consequências nada desprezíveis. Ele

por ele" DeJEAN, Joan. Antigos Contra Modernos: as guerras culturais e a construção de um fin de siècle. Rio de Janeiro: Civilização Brasileiro, 2005.

72 HAZARD, Paul. Crise da Consciência Europeia, p.88.

${ }^{73}$ Il est de notorieté publique que les ouvrages de Mr. Bayle ont rempli de doutes un grand nombre de Lecteurs, \& ont répandu de l'icertitude sur les Principes de la Religion, \& de la Morale qui étoient le plus universellement reçus. BIBLIOTHEQUE GERMANIQUE, Amsterdam, tome Dix-Huitieme, Anne MDCCXXIX [1729], p.99..

${ }^{74}$ BUTLER, Judith. O que é a crítica? Um ensaio sobre a virtude de Foucault, p.163.

${ }^{75}$ FOUCAULT, Michel. História da Sexualidade. Vol.2: o uso dos prazeres. Rio de Janeiro: Edições Graal, 1998.

${ }^{76}$ BUTLER, Judith. O que é a crítica? Um ensaio sobre a virtude de Foucault, p.163 
jamais formulou um sistema filosófico formal ou indicou um caminho a ser percorrido para um futuro utópico. Nada disso o impediu de tomar decisões, muitas das quais o colocaram em risco e levaram a grandes perdas pessoais. Dificilmente ele poderia figurar como um niilista.

Suas formulações críticas desestabilizaram os modelos dogmáticos das religiões e tiveram um papel importante da defesa da tolerância. Voltaire foi seu admirador e se valeu dos trabalhos de Bayle nas suas disputas contra a interferência da Igreja no Estado. Em um contexto em que a intolerância era regra e a tolerância exceção, ter pensado diferente parece ter sido importante: "fazer da tolerância, nessas condições, um princípio positivo, tanto sobre o plano religioso como civil, exigia uma verdadeira revolução intelectual - uma 'inversão do pensável ${ }^{77}$,". Mudança que teve consequências concretas e não só intelectuais: “depois de seus escritos, a tolerância passa a ser uma atitude positiva e uma postura política ${ }^{78}$ ".

Quando acusado de corromper os costumes ao questionar os dogmas de seu tempo, Bayle soube zombar com ironia: "Aqueles que murmuram contra a tolerância dos livros dos hereges, deviam saber que nem todos os tipos de espírito estão adequados ao jugo da Inquisição ${ }^{79}$ ".

Correto ou não, Foucault também justificou seu posicionamento intelectual vendo na própria dúvida crítica uma virtude e uma ética. De forma consciente negava-se a aderir a projetos globais que oferecem programas de conjunto para o futuro. Para a pergunta colocada acima (como saber se pensar diferente produzirá um mundo melhor?), sua resposta era que não há como saber. A atividade intelectual e a ação política e social têm de ser praticadas como ensaios:

(...) parece-me que essa atitude histórico-crítica deve ser também uma atitude experimental. Quero dizer que esse trabalho realizado nos limites de nós mesmos deve, por um lado, abrir um domínio de pesquisas históricas e, por outro, colocar-se à prova da realidade e da atualidade, para simultaneamente apreender os pontos em que a mudança é possível e desejável e para determinar a forma precisa a dar a essa mudança ${ }^{80}$.

Essa decisão, ao mesmo tempo metodológica e estratégica, passava também por uma leitura da história política de seu tempo:

Prefiro as transformações muito precisas que puderam ocorrer, há 20 anos, em um certo número de domínios que concernem aos nossos modos de ser e de pensar, às relações de autoridade, às relações de sexos, à maneira pela qual

\footnotetext{
${ }^{77}$ GROS, Jean-Michel. Fundamentos e limites de uma teoria filosófica da tolerância: o Comentário filosófico de Pierre Bayle. Revista Enunciação, Rio de Janeiro, 2017 - Vol.2 - No 2 - , p.186.

${ }^{78}$ ALMEIDA, Maria Cecília P. de. O Elogio da Polifonia: Tolerância e Política em Pierre Bayle, p.15.

${ }^{79}$ Ceux qui murmurent contre la tolerance des Livres des héretiques, doivent savoir que toutes sortes d'esprit ne sont pas propres pour le joug de l'Inquisition. BAYLE, Pierre. Nouvelles de la république des lettres, Juillet, 1685 , art. IX.

${ }^{80}$ FOUCAULT, Michel. Ditos e Escritos II. Rio de Janeiro: Forense Ed., 2015, p.365.
} 
percebemos a loucura ou a doença, prefiro essas transformações mesmo parciais, que foram feitas na correlação da análise histórica e da atitude prática, às promessas do novo homem que os piores sistemas políticos repetiram ao longo do século $\mathrm{XX}^{81}$.

Como se vê, o pensamento crítico que indaga quanto aos limites epistemológicos da racionalidade moderna não é uma atitude eticamente vazia e politicamente inconsequente. Sua trajetória, pelo menos enquanto uma atitude, tem uma longa duração. Espera-se que ao retomar essa questão numa perspectiva historiográfica se tenha conseguido indicar a pluralidade de formas pelas quais aquilo que se chama modernidade pode ser entendido. Trajetórias como a de Pierre Bayle, mas não só a sua ${ }^{82}$, sugerem que muito do que tem sido apontado como negação da Luzes, na verdade esteve no cerne de sua própria constituição.

\section{CONSIDERAÇÕES FINAIS}

A escolha dos trabalhos de Michel Foucault, como a referência em torno da qual foram articuladas as proposições desse artigo, se deu por dois motivos principais. Primeiro: seus estudos históricos abrem um itinerário no qual o próprio presente é pensado num jogo descontínuo de temas e prática que vão do período moderno ao período contemporâneo. Segundo: a forma como, através desse itinerário, ele define a crítica, indica que temas e procedimentos formulados a mais de três séculos, não são só do interesse de uma historiografia da erudição e do antiquariato.

Essa forma de abordagem é uma entre outras possíveis. Porém, ela parece particularmente interessante para um tipo de historicização da escrita da história que leve em consideração diferentes modos de produção do conhecimento histórico e formas alternativas de abordagem do passado. Modalidades e formas muitas vezes não consideradas por um tipo memória disciplinar restrita aos marcos cronológicos da institucionalização universitária da história.

Por fim, o tema da crise...

Aceitando que o diagnóstico de que o conceito moderno de história está se desfazendo (ou, que já teria se desfeito) esteja correto: deveria isso causar alarme? A hipótese de que estamos vivendo um momento inédito de experiência do tempo, no qual começa a se delinear um novo regime de historicidade, vem sendo debatida ${ }^{83}$. Mas será que um horizonte de

\footnotetext{
${ }^{81}$ FOUCAULT, Michel. Ditos e Escritos II. Rio de Janeiro: Forense Ed., 2015, p.365.

${ }^{82}$ Personagens como La Mothe La Vayer (1588-1672), Braruch Espinoza (1633-1677) e David Hume (17111776), por exemplo, são nomes que indicam a complexidade e a pluralidade do pensamento produzido no período moderno.

${ }^{83}$ PEREIRA, Mateus H.F; ARAUJO, Valdei Lopes de. Reconfigurações do tempo histórico: presentismo, atualismo e solidão na modernidade digital.
} 
expectativa não utópico tem necessariamente de ser distópico? Um futuro não percebido como promessa, só pode ser esperado como ameaça?

Não é o caso de ignorar os perigos. Pelas ondas de rádio, pelos sinais de TV e pela rede mundial de computadores não cessam de nos chegar dados alarmantes. Nos limites geográficos do Brasil em menos de dois anos assistimos um golpe de Estado, o progressivo desmonte do estado de bem-estar social e mais uma intervenção militar no Estado do Rio de Janeiro. Em um momento de claro regime de exceção assistiu-se a execução da vereadora Marielle Franco (do Psol) e do motorista que a acompanhava, Anderson Gomes. A morte de Marielle reforça terríveis estáticas do país: feminicídios, massacre da população negra e LGBTTs. De acordo com relatório produzido pela Anistia Internacional, em 2017, o Brasil é um dos países do globo que mais mata ativistas ${ }^{84}$.

Disso fica a inevitável pergunta da atualidade para os historiadores: “como nós, (...) supostamente habilitados a dar sentido a esta aflição, podemos responder — se é que podemos? Poderia a disciplina histórica, ela própria fruto de contingências históricas específicas, ser fiadora desta serventia ${ }^{85}$ ".

Uma perspectiva crítica nos informa que não há nada "cuja estabilidade, cujo enraizamento, cujo fundamento não é nunca tal que não se possa de uma maneira ou de outra, se não pensar em seu desaparecimento, ao menos identificar pelo que e a partir de que seu desaparecimento é possível ${ }^{86 "}$. Nada é garantido, mas se toda situação atual se configurou num campo de possibilidade, a reversão e dissolução dela também é possível. Cabe definir estrategicamente como os estudos históricos podem contribuir para abertura de um futuro melhor. Historiadoras e historiadores do século XXI têm muitos desafios colocados diante de si.

\section{Recebido em: 22/04/2018 Aceito em: 04/06/2018}

\section{REFERÊNCIAS BIBLIOGRÁFICAS}

AVILA, Lima de. Indisciplinando a historiografia: do passado histórico ao passado prático, da crise à crítica. Revista Maracanan, Rio de Janeiro, jan./jun. 2018.

\footnotetext{
${ }^{84}$ Para uma síntese desses dados ver https://anistia.org.br/noticias/brasil-lidera-numero-de-assassinatos-dediversos-grupos-de-pessoas-em-2017-aponta-anistia-internacional-em-novo-relatorio/ Para consulta do relatório na íntegra acessar https://anistia.org.br/wp-content/uploads/2018/02/informe2017-18-online1.pdf. Última consulta em 04/06/2018.

${ }^{85}$ AVILA, Lima de. Indisciplinando a historiografia: do passado histórico ao passado prático, da crise à crítica, p.36.

${ }^{86}$ FOUCAULT, Michel. O que é a crítica?, p.18.
} 
BALLESTRIN, Luciana Maria de Aragão. Rumo a uma teoria pós-democrática? Pelotas (RS): $41^{\circ}$ encontro da Anpocs, outubro de 2017.

BARLETT, Robert C. Introduction In: BAYLE, Pierre. Various Thoughts on The Occasion of Comet. Abany: State of New York Press, 2000, p.xxiv.

BAUMER, Franklin L. O Pensamento Europeu Moderno: séculos XVII e XVIII. volume I. Rio de Janeiro: editora 70.

CASSIRER, Ernst. A Filosofia do Iluminismo. Campinas: ed. Unicamp, 1994.

CHARTIER, Roger. À Beira da Falésia: a história entre incertezas e inquietude. Porto Alegre: Ed. da UFRGS, 2002.

FOUCAULT, Michel. Ditos e Escritos II. Rio de Janeiro: Forense Ed., 2015.

GADAMER, Hans-Georg. Verdade e Método: traços fundamentais de uma hermenêutica filosófica. Petrópolis: Vozes, 1997.

GILROY, Paul. O Atlântico Negro: modernidade e dupla consciência. São Paulo: editora 34, 2001.

GINZBURG, Carlo. Relações de Força. História, Retórica, Prova. São Paulo: Cia das Letras, 2004.

HARTOG, François. Crer em História. Belo Horizonte: Autêntica, 2017.

HARTOG, François. Regimes de Historicidade: presentismo e experiências do tempo. Belo Horizonte: Autêntica, 2014.

HAZARD, Paul. Crise da Consciência Europeia. Lisboa: Cosmos, 1971.

HIMMELFARB, Gertrude. The Roads to Modernity: the British, French, and American Enlightenments. Vintage Books, 2005.

HIMMELFARB, Gertrude. The Roads to Modernity: the British, French, and American Enlightenments.

JENKINS, Keith; MORGAN, Sue; MUNSLOW, Alun (orgs). Manifestos for History. London: Routledge, 2007.

KOSELLECK, Reinhart. Crítica e Crise - Uma contribuição à patogênese do mundo burguês. Rio de Janeiro: Contraponto/EdUERJ, 1999.

MOMigliAnO, Arnaldo. História Antiga e o Antiquário. Anos 90, Porto Alegre, v.21, n.39, 2014.

PEREIRA, Mateus H.F; ARAUJO, Valdei Lopes de. Reconfigurações do tempo histórico: presentismo, atualismo e solidão na modernidade digital. Revista UFMG, Belo Horizonte, 2016, v.23, N. 1 e 2.

PULIAN, Pierre. Critique des lettres pastorales de M. Jurieu. Lyon: Anisson, Posuel \& Rigaud, MDCLXXXIX [1689].

SANTAELLA, Lucia. Pós-humano - por quê? São Paulo: Revista USP, n.74, junho/agosto 2007.

FOUCAULT, Michel. Ditos e Escritos II. Rio de Janeiro: Forense Ed., 2015. 
GROS, Jean-Michel. Fundamentos e limites de uma teoria filosófica da tolerância: o Comentário filosófico de Pierre Bayle. Revista Enunciação, Rio de Janeiro, 2017 - Vol.2 - No 2.

ALMEIDA, Maria Cecília P. de. O Elogio da Polifonia: Tolerância e Política em Pierre Bayle. FOUCAULT, Michel. História da Sexualidade. Vol.2: o uso dos prazeres. Rio de Janeiro: Edições Graal, 1998. 